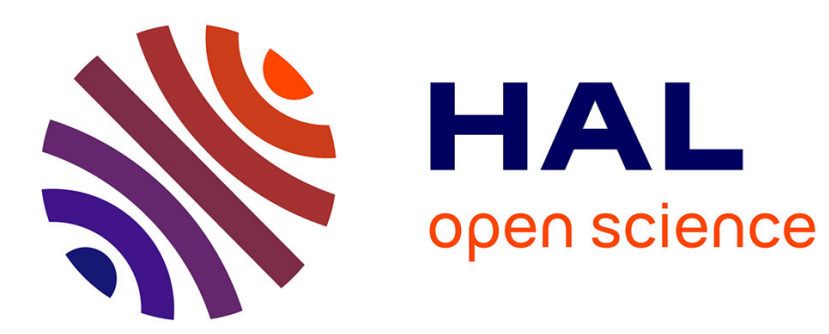

\title{
Prediction and analysis of GBAS integrity monitoring availability at LinZhi airport
}

Zhipeng Wang, Christophe Macabiau, Jun Zhang, Anne-Christine Escher

\section{To cite this version:}

Zhipeng Wang, Christophe Macabiau, Jun Zhang, Anne-Christine Escher. Prediction and analysis of GBAS integrity monitoring availability at LinZhi airport. GPS Solutions, 2014, 18 (1), pp 27-40. 10.1007/s10291-012-0306-4 . hal-00937606

\section{HAL Id: hal-00937606 \\ https://hal-enac.archives-ouvertes.fr/hal-00937606}

Submitted on 25 Nov 2014

HAL is a multi-disciplinary open access archive for the deposit and dissemination of scientific research documents, whether they are published or not. The documents may come from teaching and research institutions in France or abroad, or from public or private research centers.
L'archive ouverte pluridisciplinaire HAL, est destinée au dépôt et à la diffusion de documents scientifiques de niveau recherche, publiés ou non, émanant des établissements d'enseignement et de recherche français ou étrangers, des laboratoires publics ou privés. 


\title{
Prediction and analysis of GBAS integrity monitoring availability at LinZhi airport
}

\author{
ZhiPeng Wang $\cdot$ Christophe Macabiau • \\ Jun Zhang $\cdot$ Anne-Christine Escher
}

Received: 18 May 2012/ Accepted: 15 December 2012/Published online: 3 January 2013

(C) Springer-Verlag Berlin Heidelberg 2012

\begin{abstract}
Prediction and analysis of GBAS integrity monitoring is important, especially at the airports where a GBAS station it to be installed. Based on existing standard documents and published research, we present a software tool for GBAS availability prediction. Simulations have been conducted that include single point, single approach path, and multiple repetitions of a same approach path in order to analyze the availability of GNSS signal integrity monitoring with a GBAS at LinZhi airport. The results show that the long-term 24-h service availability figure at two typical single points along the approach path for GBAS Approach Service Type C (GAST C) is above $99.999 \%$ for each point, and for GBAS Approach Service Type D (GAST D) at three typical single points, it is lower than $99.8 \%$ for each point. The unavailability percentage over a 24 -h period is 0.76 and $2.40 \%$ for GAST C and GAST D, respectively. The results of sensitivity tests show that the impact of the mask angle and the latitude on the GBAS availability at LinZhi airport are more important than that of the constellation. Our conclusions could also be of interest for the implementation of GBAS stations at other plateau airports.
\end{abstract}

\footnotetext{
Z. Wang $(\bowtie) \cdot$ J. Zhang

National Key Laboratory of CNS/ATM, School of Electronic and Information Engineering, Beihang University,

Beijing 100191, China

e-mail: wangzp1818@gmail.com

C. Macabiau · A.-C. Escher

Signal Processing and Navigation Group, TELECOM Lab, SINA department, Ecole Nationale de l'Aviation Civile (ENAC), Toulouse, France

e-mail: macabiau@ recherche.enac.fr
}

Keywords GBAS · Prediction · Integrity monitoring availability · GAST D

\section{Introduction}

Ground-based augmentation system (GBAS) currently supports precise and safe navigation that meets the requirements of Category I and is even anticipated to meet Category II/III aircraft precision approach requirements (EUROCAE ED114 2003; RTCA DO245A 2004; RTCA DO253C 2008; RTCA DO246D 2009). However today, there is little information available about any existing GBAS Approach Service availability prediction tool. However, it is necessary for the airborne user who intends to fly an approach using GLS (GBAS Landing System) to know whether the GBAS Approach Service is available before approaching and landing at the airport. Therefore, based on the existing standard documents and published works, we describe the development of a software tool that allows GBAS integrity monitoring availability prediction. We then use that tool to analyze the GBAS Approach Service at LinZhi airport.

LinZhi airport, International Air Transport Association (IATA) code LZY and International Civil Aviation Organization (ICAO) code ZUNZ, is a typical plateau airport with altitude of about $2,949 \mathrm{~m}$ and located in Tibet. It is surrounded by high mountains that are clouded with mist. Aircrafts take off and land in narrow windy valleys: the distance between the flight path and the sides of the valley at the narrowest points is less than $4 \mathrm{~km}$. Hence, the accuracy and the coverage of the traditional navigation aids, such as the Instrument Landing System (ILS), are limited. Moreover, strong winds and a large temperature difference between day and night at the airport location 
significantly shorten the lifespan of the equipment. Fortunately, GPS with GBAS augmentation is capable of providing safe and reliable guidance, with greatly improved flexibility in the design of the approach flight path. Furthermore, since the maintenance of only one reference system at each airport is necessary, GPS will be more cost effective than traditional navigation systems (Dautermann et al. 2012).

The GBAS availability prediction tool has been developed according to local area augmentation system (LAAS) requirements (RTCA DO245A 2004; RTCA DO253C 2008; RTCA DO246D 2009), because the standards and models of LAAS have not yet been adopted by ICAO completely, especially for GBAS Approach Service Type C (GAST C) and GBAS Approach Service Type D (GAST D) (ICAO Annex 10 2010). Even though the analysis has been conducted for LinZhi airport, we expect the results be helpful for the design and development of similar plateau airports such as Innsbruck airport in Austria or Juneau airport in America.

\section{Requirements of GBAS}

According to RTCA DO245A (2004) for Approach Service, the integrity risk due to undetected positional errors relative to the GBAS reference point, greater than the associated Protection Levels (PLs) under normal and faulted measurement conditions, is $0.5 \times 10^{-7}$ per approach for GAST C and $0.25 \times 10^{-9}$ per approach for GAST D. However, a recent ICAO Navigation Systems Panel (NSP) (2010a) technical report proposed to modify GAST D value to $0.5 \times 10^{-7}$ per approach. Note that the last value has been used by DLR in their GAST D tests (Dautermann et al. 2012).

Since the performance requirement on the vertical axis is more stringent than on the lateral axis, only the vertical axis of GBAS Approach Service will be discussed. The vertical alert limit is defined in Table 2-15 of RTCA DO253C (2008) and presented in Table 1.

The Final Approach Segment Vertical Alert Limit (FASVAL) is lower than $10 \mathrm{~m}$ according to Table 3-8 of RTCA DO245A (2004). The value of $10 \mathrm{~m}$ is chosen for FASVAL in our simulations. This value is also adopted by DLR in GAST D tests in Dautermann et al. (2012). $\mathrm{H}$ is the

Table 1 Vertical alert limit (RTCA DO253C 2008)

\begin{tabular}{ll}
\hline Vertical alert limit $(\mathrm{m})$ & $H(\mathrm{~m})$ \\
\hline FASVAL & $H \leq 60.96$ \\
$0.095965 \mathrm{H}+$ FASVAL-5.85 & $60.96<H \leq 408.432$ \\
FASVAL +33.35 & $\mathrm{H}>408.432$ \\
\hline
\end{tabular}

product of $\sin$ (GPA), where GPA is Glide Path Angle, and the slant distance from the aircraft position to the Glide Path Intercept Point (GPIP).

\section{Measurements error model for GBAS Approach Service availability prediction}

This section presents the mathematical models used in the GBAS availability prediction, including the models for GAST C and GAST D PLs, the user differential range error, the B and D values, and the onboard monitors of GAST D approach. Based on those models, the software tool for GBAS availability prediction will be described in the next section.

\section{GAST C and GAST D protection levels}

The GBAS vertical protection level (VPL) computed for an Approach operation $\left(\mathrm{VPL}_{\mathrm{Apr}}\right)$ is the maximum of the VPL computed under the $\mathrm{H}_{0}$ hypothesis $\left(\mathrm{VPL}_{\mathrm{Apr} \_\mathrm{HO}}\right)$ and the VPL computed under the $\mathrm{H}_{1}$ hypothesis $\left(\mathrm{VPL}_{\mathrm{Apr} \_\mathrm{H} 1}\right)$ (RTCA DO253C 2008). First, VPL Apr_Ho $_{-}$is given as

$\mathrm{VPL}_{\mathrm{Apr} \_\mathrm{H} 0}=K_{\mathrm{ffmd}} \sqrt{\sum_{i=1}^{N} s_{\mathrm{Apr} \_ \text {vert }, i}^{2} \sigma_{i}^{2}}+D_{V}$

where $K_{\mathrm{ffm}}$ is a multiplier determined by the probability of fault-free missed detection, which is in turn determined by the integrity risk (RTCA DO245A 2004), $i$ is the ranging source index, $N$ is the number of ranging sources used in the position solution, $S_{\mathrm{Apr} \_ \text {vert }, i}$ is projection of the vertical component and translation of the along track errors into the vertical for $i$ th ranging source, and $D_{V}$ is a parameter that depends on the active Approach Service Type. For GAST C, we use $D_{V}=0$; for GAST D, the value $D_{V}$ will be discussed in the section "Model of the $\mathrm{D}$ value". The symbol $\sigma_{i}$ is the pseudorange standard deviation term for the $i$ th ranging source. It is computed as

$\sigma_{i}^{2}=\sigma_{\mathrm{pr} \_ \text {gnd_ } \_ \text {, }, i}^{2}+\sigma_{\text {tropo }, i}^{2}+\sigma_{\mathrm{iono}, i}^{2}+\sigma_{\mathrm{air}, i}^{2}$

where $\sigma_{\mathrm{pr} \_ \text {gnd_x }, i}$ is the total (post correction) fault-free noise term provided by the ground function (via the VDB) for satellite $i, \sigma_{\text {tropo, } i}$ is computed by the airborne equipment to cover the residual tropospheric error for satellite $i$, $\sigma_{\text {iono, } i}$ is the residual ionospheric delay (due to spatial decorrelation) uncertainty for the $i$ th ranging source, and $\sigma_{\mathrm{air}, i}$ is the standard deviation of the aircraft contribution to the corrected pseudorange error for the $i$ th ranging source.

$\mathrm{VPL}_{\mathrm{Apr} \_\mathrm{H} 1}$ is computed as (RTCA DO253C 2008)

$\mathrm{VPL}_{\mathrm{Apr} \_\mathrm{H} 1}=\max \left(\mathrm{VPL}_{\mathrm{Apr} \_\mathrm{H} 1, j}\right)+D_{V}$ 
where $\mathrm{VPL}_{\mathrm{Apr} \_\mathrm{H} 1, j}$ is calculated as

$\mathrm{VPL}_{\mathrm{Apr} \_\mathrm{H} 1, j}=\left|B_{j \_\mathrm{Apr} \_ \text {vert }}\right|+K_{\mathrm{md}} \sqrt{\sum_{i=1}^{N} s_{\mathrm{Apr} \_ \text {vert }, i}^{2} \sigma_{i, \mathrm{H} 1}^{2}}$

with

$$
\begin{aligned}
& B_{j \_ \text {Apr_vert }}=\sum_{i=1}^{N} s_{\text {Apr_vert }, i} B_{i, j} \\
& \sigma_{i, \mathrm{H} 1}^{2}=\frac{M_{i} \cdot \sigma_{\mathrm{pr} \_ \text {gnd_x }, i}^{2}}{U_{i}}+\sigma_{\text {tropo }, i}^{2}+\sigma_{\text {air }, i}^{2}+\sigma_{\text {iono }, i}^{2}
\end{aligned}
$$

and $j$ is the ground subsystem reference receiver index for all $j$ in 1 to $\max \operatorname{MAX}\left\{M_{i}\right\}$, with $M_{i}$ being the number of reference receivers used to compute the pseudorange corrections for the $i$ th ranging source, $K_{\mathrm{md}}$ is a multiplier (unitless) determined by the probability of missed detection given that the ground subsystem is faulted (RTCA DO245A 2004), $B_{i, j}$ is the $B$ value for the $i$ th satellite and $j$ th reference receiver, $M_{i}$ is the number of reference receivers used to compute the pseudorange corrections for the $i$ th ranging source, and $U_{i}$ is the number of reference receivers used to compute the pseudorange corrections for the $i$ th ranging source, excluding the $j$ th reference receiver.

The vertical ephemeris error position bounds are also given by RTCA DO253C (2008),

$\mathrm{VPB}_{\mathrm{Apr} \_e}=\max \left(\mathrm{VPB}_{\mathrm{Apr} \_e, k}\right)+D_{V}$

where $\mathrm{VPB}_{\mathrm{Apr} \_ \text {e, } k}$ is the vertical ephemeris error position bound relative to the selected approach segment for the $k$ th GPS source used in the position solution. It is computed for all GPS ranging sources used in the position solution, as

$$
\begin{aligned}
\mathrm{VPB}_{\mathrm{Apr} \_\mathrm{e}, k}= & \left|s_{\mathrm{Apr} \_ \text {vert }, k}\right| x_{\text {air }} P_{k \_\mathrm{x}} \\
& +K_{\mathrm{md} \_\mathrm{e} \_\mathrm{x}} \sqrt{\sum_{i=1}^{N} s_{\mathrm{Apr} \_ \text {vert }, i}^{2} \sigma_{i}^{2}}
\end{aligned}
$$

where $x_{\text {air }}$ is the slant range distance (in $\mathrm{m}$ ) between current aircraft location and the reference point, $i$ is the index of ranging sources used in the position solution, $P_{k_{-} \mathrm{x}}$ is the broadcast ephemeris decorrelation parameter for the $j$ th ranging source, which is set to $0.00015 \mathrm{~m} / \mathrm{m}$ in Section F3.4 of RTCA DO245A (2004), and $K_{\text {md_e_x }}$ is the appropriate broadcast ephemeris missed detection multiplier for the approach associated with the satellite constellation for the $j$ th ranging source. In Table B-3 of RTCA DO246D (2009), the suggested values for $K_{\text {md_e_C,GPS }}$, and $K_{\text {md_e_D,GPS }}$ are 5.0 and 5.6, respectively.

According to Section 2.3.11.5.2.1 of RTCA DO253C (2008), the airborne GBAS system will raise a flag as being unavailable if $\mathrm{VPL}_{\mathrm{Apr}}$ or $\mathrm{VPB}_{\mathrm{Apr} \_} \mathrm{e}$ exceeds the vertical alert limit. Therefore, VPL is defined as the maximum of $\mathrm{VPL}_{\mathrm{Apr}}$ and $\mathrm{VPB}_{\mathrm{Apr} \_\mathrm{e}}$.

User differential range error models

SIS pseudorange accuracy model $\sigma_{\text {pr_gnd_x } i}$ depends on the Approach Service Type that is currently in use. However, there is no model available for GAST D in the standard documents or published studies. Additionally, the ground accuracy bound should not be really impacted by the change in code-carrier smoothing time constant because it is a bound to several errors sources (Neri et al. 2010). Therefore, for GAST C and D, the same model is used in our simulations and is given as

$\sigma_{\text {pr_gnd }}\left(\theta_{i}\right)=\sqrt{\frac{\left(a_{0}+a_{1} \mathrm{e}^{-\theta_{i} / \theta_{0}}\right)^{2}}{M}+a_{2}^{2}}$

where $M$ is the number of reference receivers, $i$ is the $i$ th ranging source, $\theta_{i}$ is the ranging source elevation angle for ground station receivers, and $a_{0}, a_{1}, a_{2}$, and $\theta_{0}$ depend on the level of Ground Accuracy Designators (GAD) (i.e., A, $\mathrm{B}$ and $\mathrm{C}$ ) as defined in Table 3-1 of RTCA DO245A (2004).

The residual tropospheric uncertainty is defined in Section 2.3.12.2 of RTCA DO253C (2008) as

$\sigma_{\text {tropo }}\left(\theta_{i}\right)=\sigma_{N} h_{0} \frac{10^{-6}}{\sqrt{0.002+\sin ^{2}\left(\theta_{i}\right)}}\left(1-e^{\frac{-\Delta h}{h_{0}}}\right)$

where $\theta_{i}$ is the elevation angle, $\sigma_{N}$ is the refractivity uncertainty transmitted by the ground subsystem, and $h_{0}$ is the troposphere scale height transmitted by the ground subsystem (in m). The values for $\sigma_{N}$ and $h_{0}$ are set to 34 and $7,600 \mathrm{~m}$, respectively, as in Section F3.4 of RTCA DO245A (2004). The difference $\Delta h$ in altitude between airborne and ground subsystems (in $\mathrm{m}$ ) changes with time.

Similar to $\sigma_{\text {pr_gnd_x }, i}$, the residual ionospheric delay uncertainty $\sigma_{\text {iono }, i}$ also depends on the Approach Service Type. For GAST C, the value for $\sigma_{\text {iono, } i}$ is set based on $\sigma_{\text {vert_iono_grad }}$ broadcast in Message Type (MT) 2; for GAST D, it is set based on $\sigma_{\text {vert_iono_grad_D }}$ transmitted by the MT 2 additional data block. The parameter $\sigma_{\text {vert_iono_grad_D }}$ differs from $\sigma_{\text {vert_iono_grad }}$ in that the former should include no adjustment to address overbounding of anomalous errors according to Section 2.4.4.2 of RTCA DO246D (2009). However, since there is no reference value for $\sigma_{\text {vert_iono_grad_D}}$, an increased value of $4 \mathrm{~mm} / \mathrm{km}$ is used in our simulations, similar to the strategy adopted by DLR (Dautermann et al. 2012). The residual ionospheric uncertainty for a given satellite is thus (RTCA DO245A 2004; RTCA DO253C 2008):

$\sigma_{\text {iono }}=F_{\text {pp }} \times \sigma_{\text {vert_iono_grad }} \times\left(x_{\text {air }}+2 \times \tau \times v_{\text {air }}\right)$ 
where $F_{\mathrm{pp}}$ is the vertical-to-slant obliquity factor (unitless) for a given satellite, $\chi_{\text {air }}$ is the same as the one in Eq. (8), $\tau$ equals to $100 \mathrm{~s}$ both for GAST C and GAST D as in Table 2-18 of RTCA DO253C (2008), and $v_{\text {air }}$ is the aircraft horizontal approach velocity, which is assumed to be $77 \mathrm{~m} / \mathrm{s}$ for GAST C and $72 \mathrm{~m} / \mathrm{s}$ for GAST D as in Section F3.3 of RTCA DO245A (2004).

For GAST C, the total aircraft contribution includes the receiver contribution and a standard allowance for airframe multipath as

$\sigma_{\text {air }, i}^{2}\left(\theta_{i}\right)=\sigma_{\text {receiver }}^{2}\left(\theta_{i}\right)+\sigma_{\text {multipath }}^{2}\left(\theta_{i}\right)$

$\sigma_{\text {receiver }}\left(\theta_{i}\right)=a_{0}+a_{1} \mathrm{e}^{-\left(\theta_{i} / \theta_{0}\right)}$

$\sigma_{\text {multipath }}\left(\theta_{i}\right)=a_{0}+a_{1} \mathrm{e}^{-\left(\theta_{i} / \theta_{0}\right)}$

where $i$ is $i$ th ranging source, $\theta_{i}$ is the ranging source elevation angle for the $i$ th ranging source, and $a_{0}, a_{1}$, and $\theta_{0}$ depend on either the level of airborne accuracy designators (AAD) (Eq. (13)) or airborne multipath designators (AMD) (i.e., A and B) in Eq. (14)) as defined in Sections 3.3.1.1 and 3.3.1.3 of RTCA DO245A (2004).

For GAST D, in addition to the contributions of receiver and multipath, the $\sigma_{\mathrm{air}, i}$ should also include the effects of code-carrier divergence. Since no standardized model is available, the model proposed by Neri et al. (2010) is used in the simulations,

$\sigma_{\text {air_GASTD }, i}=\sqrt{100 / 30} \cdot \sigma_{\mathrm{air}, i}$

This model takes into account the different code-carrier smoothing time constant.

Model of the $B$ value

Since the simulation of pseudorange corrections is complex and not necessary to analyze PLs, models for the $B$ value are often used. When computing the PLs, a $B_{\max }$ equal to $20 \mathrm{~cm}$ is used (Bruckner et al. 2011a, b). In our simulations, the $\mathrm{B}$ value is replaced by its threshold which is determined by the fault-free standard deviation of the $\mathrm{B}$ values using the equation (FAA 2005; Dautermann et al. 2012; Xie et al. 2001),

$B_{i, j}=K_{B} \frac{\sigma_{\mathrm{pr} \_ \text {gnd }}\left(\theta_{i}\right)}{\sqrt{M_{n}-1}}$

where $K_{B}$ is a station configurable parameter between 5 and 6 that can be selected by the manufacturer in order to meet the continuity requirements. The value of 5.6 is commonly chosen in publications (Xie et al. 2001).

Model of the $D$ value

$D_{V}$ is the magnitude of the vertical projection of the difference between the 30 and $100 \mathrm{~s}$ smoothed position solutions. A simplified model for the $D$ value was suggested by Mats Brenner of Honeywell and Tim Murphy of Boeing as mentioned by Shively and Hsiao (2010). In the model, it is assumed that $D_{R}$ primarily reflects only the difference in the corrected range errors due to ionospheric delay. In addition, a model for the bound of $D_{v}$ is mentioned in Section A.4.2.2 of ICAO NSP (2009). By combining these 2 models together, the following model for the D value can be obtained

$T\left(D_{V}\right)=K_{\mathrm{fd} D} \times \sqrt{\sum_{i=1}^{N} S_{\mathrm{Apr} \_ \text {vert }, i}^{2} \times \sigma_{D_{R}}^{2}}$

$\sigma_{D_{R}}=F_{\text {pp }} \times \sigma_{\text {vert_iono_grad }} \times 140 \times v_{\text {air }}$

where $K_{\mathrm{fdD}}$ is equal to 5.5 according to a continuity risk of $4 \times 10^{-8}$; and $F_{\mathrm{pp}}, \sigma_{\text {vert_iono_grad }}$ and $v_{\text {air }}$ are the same as given in the model of the ionospheric residual uncertainty.

Onboard monitors of GAST D approach

A code-carrier difference (CCD) monitor is used in GBAS to detect abnormally large gradients in the ionospheric delay that could cause unacceptable errors in the differential position solution. The impact of the CCD monitor that could raise a detection flag should be taken into account. However, the code and phase measurements used in the CCD monitor are not related to the satellite geometry, which is the major factor for the GAST D implementation at LinZhi airport (ICAO NSP 2010b). Moreover, there is no published statistical model for the CCD. Therefore, to reflect GBAS integrity monitoring availability under normal ionospheric conditions, it is assumed that all visible satellites could pass CCD monitor in the simulations. This is consistent with the approaches presented in other publications where the CCD has also not been considered in GAST D simulations (Shively 2004; Harris and Murphy 2007). It is, however, important to note that $S_{\text {Apr_vert }}$ presented initially is used to trigger satellite geometry screening when it exceeds a threshold, and that the value of $D_{v}$ increases with the value of $S_{\text {Apr_vert. For any }}$ single satellite, the assumed limit of $S_{\text {Apr_vert }}$ is 4 , and for any pair of satellites, the assumed limit is 6 (Dautermann et al. 2012; Harris and Murphy 2007; Shively and Hsiao 2010). In the simulation, if the value for any $S_{\mathrm{Apr} \_ \text {vert }}$ exceeds 4 , or the sum of the value for any pair of satellites exceeds 6 , the satellite whose $S_{\text {Apr_vert }}$ value is the largest will be removed. For $D_{v}$, the limit is $2 \mathrm{~m}$ (RTCA DO253C 2008).

The flow chart for computing GAST D VPL is presented in Fig. 1, and the key steps are described. At each epoch we have,

Step 1 Compute the number of visible satellites (abbreviated as "Count_SV"). If Count_SV is less than 4 , set GAST D VPL to 0 ; otherwise, carry out 
Fig. 1 Flow chart for dual solution ionospheric gradient monitoring and satellite geometry screening algorithm

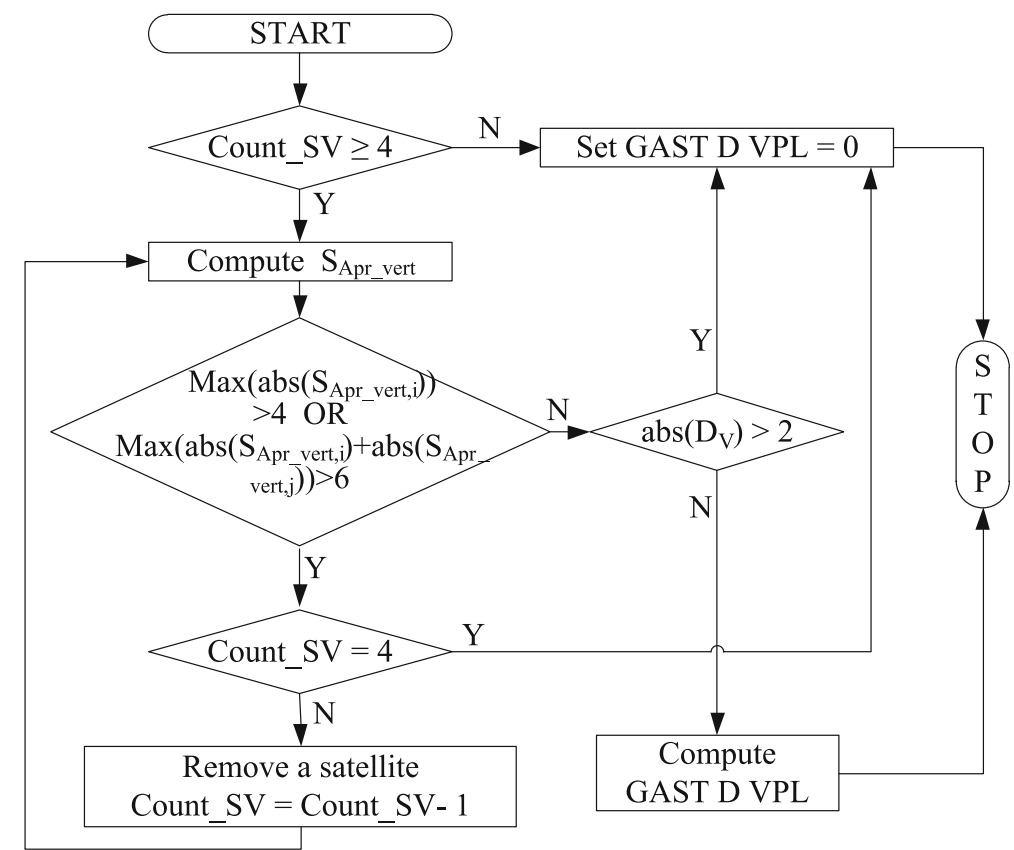

Step 2. GAST D VPL is equal to 0 indicates that the GBAS system could not meet the requirements of Approach Service Type D at that epoch

Step 2 Compute the value of $S_{\text {Apr_vert }}$. If the maximum of the absolute value of $S_{\text {Apr_vert, } i}$ is bigger than 4 for any single satellite $i$, or the maximum of the sum of the absolute value of $S_{\mathrm{Apr} \_ \text {vert }, i}$ and $S_{\mathrm{Apr} \_ \text {vert }, j}$ is bigger than 6 for any pair of satellites $i$ and $j$, continue Step 3. Otherwise, perform Step 4

Step 3 Compute the value of Count_SV. If Count_SV is equal to 4, set GAST D VPL to 0; otherwise, remove the satellite whose $S_{\text {Apr_vert }}$ value is the biggest one and return to Step 2

Step 4 Compute the absolute value of $D_{v}$. If it is greater than 2, set GAST D VPL to 0; otherwise, compute GAST D VPL

Fig. 2 Functions of the GBAS availability prediction software

\section{Software of GBAS availability prediction}

As shown in Fig. 2, the GBAS availability prediction software has two functions: a single point prediction and a flight path prediction. The two functions focus on the Approach Service, including GAST C and GAST D.

For the single point prediction, two results are displayed: the rate of long-term service availability and the plot of the computed PLs versus the required alarm levels (ALs). The long-term service availability is evaluated by assessing availability of the GBAS integrity monitoring function over a 24-h time-period, using a time-grid sampled every $5 \mathrm{~min}$, and its formula is presented in Shively $(1993,2004)$. For the flight path prediction, there are also two results displayed, the availability (Yes or No) and the plot of the computed PLs versus the required ALs.

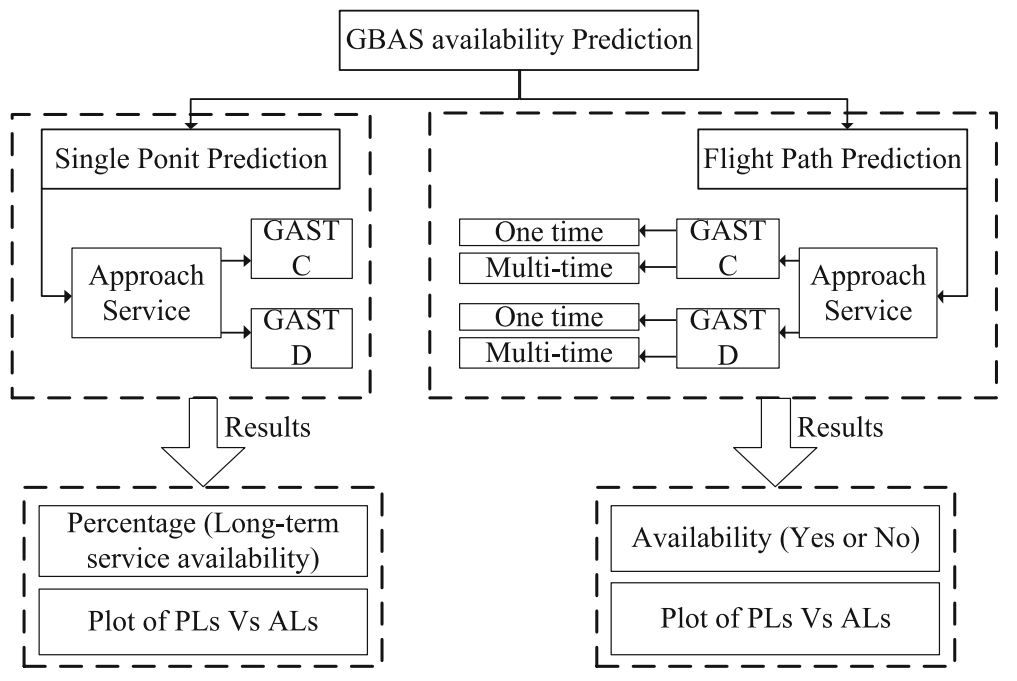




\section{Simulation and discussion}

The terrain data of LinZhi airport and simulation configuration are first presented. Then, the simulations including single point and approach are conducted. Finally, the impact of several parameters such as mask angle, constellation, and latitude, on the service availability is simulated and analyzed in detail.

Terrain data

The terrain data of LinZhi airport (Fig. 3, bottom) used in the simulations were obtained from the contours and the approach flight path of the flight procedure shown in top panel. The altitudes of the three high mountains surrounding the airport are 3,353,3,962, and 4,672 m.

In the simulations, the mask angle for each satellite takes into account not only the receiver mask angle but also the terrain masking. According to Sections 2.3.6.1 of RTCA DO253C (2008) and 3.3.1.1 of RTCA DO245A (2004), the minimum receiver mask angle for GAST C is $5^{\circ}$. But there is no limitation mentioned in the existing standardization documents for GAST D. Therefore, in the simulations, we use a $5^{\circ}$ receiver mask angle for both GAST C and GAST D. Fig. 4 shows the mask angle used as a function of the satellite azimuth; in that figure, the user is assumed to be at the starting point of the approach.

\section{Simulation configuration}

The GBAS ground facility reference receiver position depends on the airport terrain. The distance between the reference point of a GAST D ground subsystem and the threshold of any runway for which the ground subsystem supports GAST D shall be less than or equal to $5 \mathrm{~km}$ as stated in Section 3.5.7.1.4.1 of ICAO NSP (2010b). Yet,
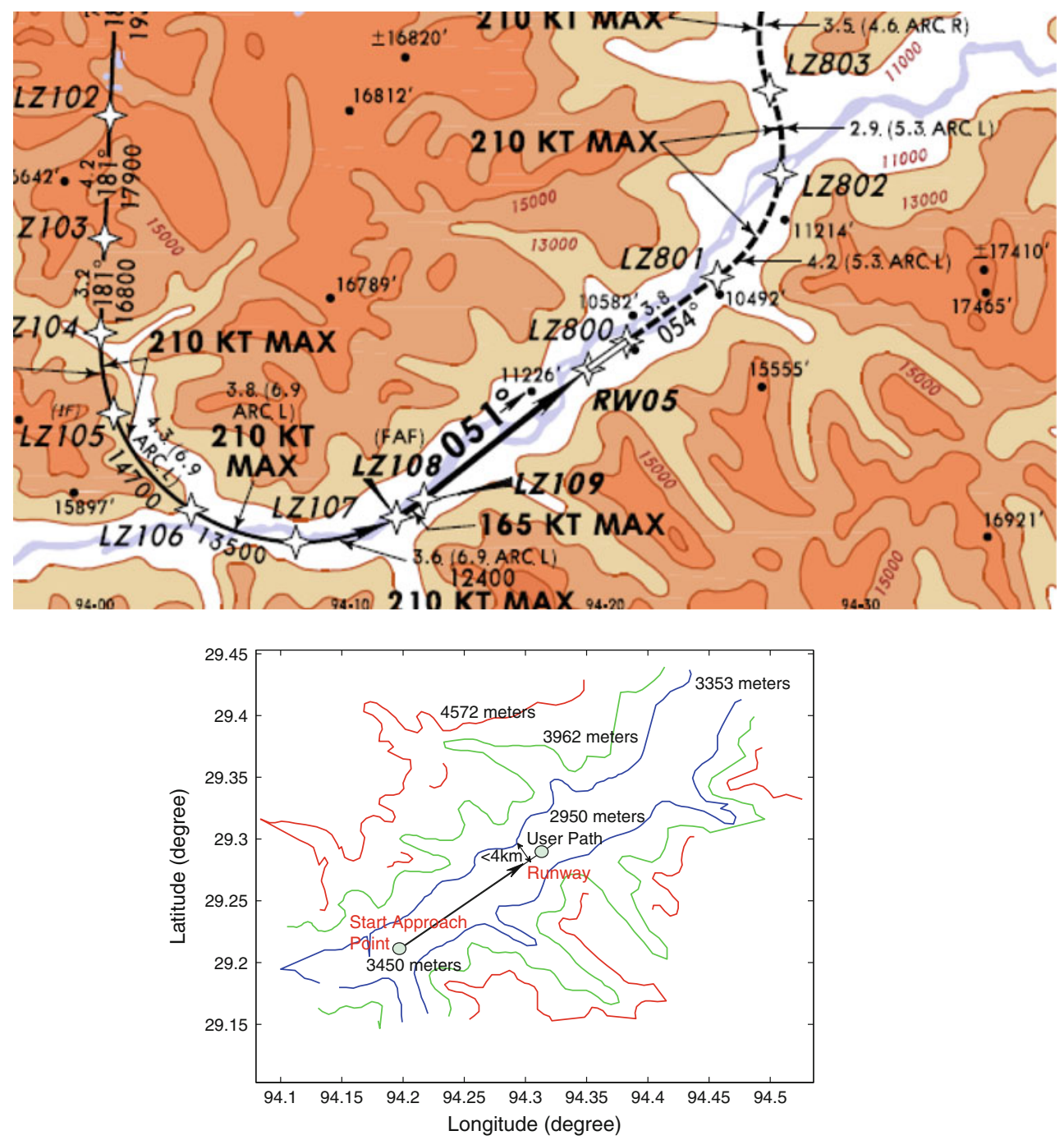

Fig. 3 Terrain data of LinZhi airport. Approach flight procedure of LinZhi airport (top), terrain data used in simulation (bottom) 


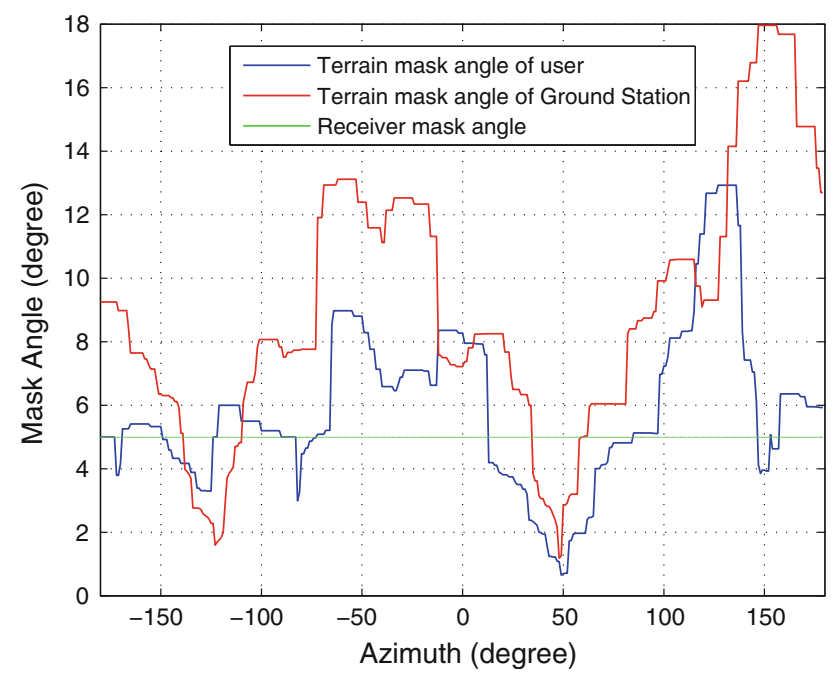

Fig. 4 Satellite signals masking at the starting point of the approach from the user point of view

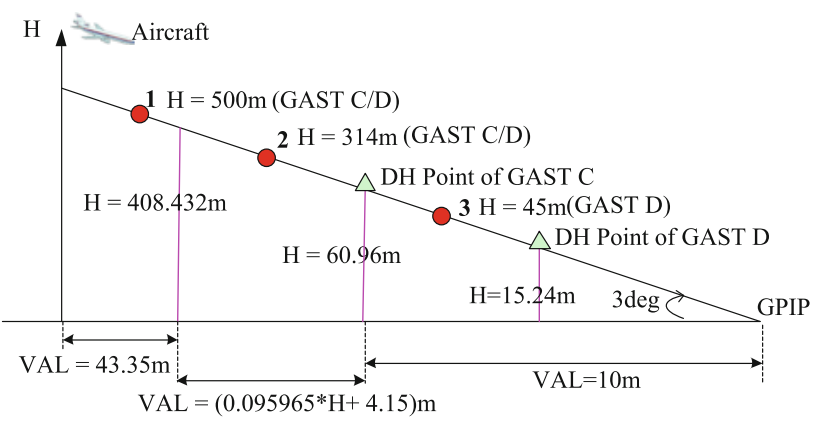

Fig. 5 Simulation scenarios of LinZhi airport

Table 2 Positions of the points used in simulations

\begin{tabular}{llll}
\hline Position & $\begin{array}{l}\text { Latitude } \\
(\mathrm{N}, \text { deg })\end{array}$ & $\begin{array}{l}\text { Longitude } \\
(\mathrm{E}, \mathrm{deg})\end{array}$ & $\begin{array}{l}\text { Altitude } \\
(\mathrm{m})\end{array}$ \\
\hline Ground Stations Center & 29.2955 & 94.3222 & 2,952 \\
GPIP & 29.2955 & 94.3222 & 2,950 \\
DH Point of GAST C & 29.2892 & 94.3129 & 3,015 \\
DH Point of GAST D & 29.2939 & 94.3199 & 2,965 \\
Point 1 (GAST C/D) & 29.2435 & 94.2445 & 3,450 \\
Point 2 (GAST C/D) & 29.2625 & 94.2735 & 3,264 \\
Point 3 (GAST D) & 29.2908 & 94.3150 & 2,995 \\
\hline
\end{tabular}

Pullen et al. (2001) mentioned that $5.5 \mathrm{~km}$ should be sufficient for most airports. Shively (2004) assumed that the LAAS Ground Facility (LGF) reference receiver centroid is at Glide Path Intercept Point (GPIP). In fact, that last one is the optimal position for GBAS ground facility because the closer the distance between the aircraft and the DH points, the shorter the distance $\chi_{\text {air }}$ between the aircraft and the reference point, and the lower the computed VPL (see (8) and (11)). Since the GBAS ground facility of LinZhi airport has not yet been determined by Civil Aviation Administration of China (CAAC), Shively's assumption is used for the simulations.

Three kinds of simulations, including single point, single approach, path, and multiple approaches are conducted. In case of single point simulations, three typical points are chosen to correspond to the three vertical alarm limit ranges mentioned in Table 1. They are named Point 1, Point 2, and Point 3 and marked by the red dots in Fig. 5 . Because Point 3 is lower than the Decision Height (DH) of GAST C, it is only used in case of GAST D assumption. For approach path simulations, with GAST C and GAST D assumption, the approach start point is Point 1 . Table 2 lists the positions of key points.

For GAST C, GAD B3 is chosen as the minimum ground station receiver requirement- $\mathrm{B}$ is for the accuracy designator and 3 is the number of ground subsystem reference receivers. For GAST D, based on the suggestion in Section F4.2 of RTCA DO245A (2004) and the assumption adopted by Shively (2004) and Harris and Murphy (2007), the minimum ground station receiver requirement is GAD C4. However, in the GAST D experiments by DLR (Dautermann et al. 2012), three receivers with better performance than GAD $\mathrm{C}$ were used; therefore, in our simulations, the minimum ground station receiver requirement for GAST D is finally set to GAD C3. According to Section 2.3.6.8.1.1 of RTCA DO 253C (2008), the minimum airborne receiver requirement is AAD A or AAD B for GAST C, and AAD B for GAST D. Table 3 summarizes the simulation cases for GAST $\mathrm{C}$ and GAST D; in that table, $\mathrm{M}$ is the number of ground subsystem reference receivers.

Simulation results for single point simulations

In those simulations, the baseline 24-slot constellation is used (DoD 2008). The time-grid length is $86,400 \mathrm{~s}$; it is sampled every $1 \mathrm{~s}$. When computing the long-term service availability, the sampling interval is $5 \mathrm{~min}$.

The results for GAST C and GAST D are illustrated in Figs. 6 and 7. Figure 6 shows that, at Point 2, the VPLs computed in Case 2 are bigger than those computed in Case 1. In Fig. 7, the point where VPL is equal to zero indicates the epoch when the Approach Service Type switches from

Table 3 Simulation cases for GAST C and GAST D

\begin{tabular}{llllll}
\hline & Case & GAD & M & AAD & AMD \\
\hline GAST C & Case 1 & C & 4 & B & B \\
& Case 2 & B & 3 & A & A \\
GAST D & Case 1 & C & 4 & B & B \\
& Case 2 & C & 3 & B & B \\
\hline
\end{tabular}


$D$ to $C$ (referred as 'ASTS', hereinafter): this may be caused by the dual solution ionospheric gradient monitoring or by the satellite geometry screening mentioned above. The numerical results of the single point simulations are presented in Table 4 . One sees that the long-term service availability of GAST C is $99.999 \%$ at the two points. However, for GAST D, the value is less than $99.8 \%$ at the three point locations. Even though the largest visible satellites number is at Point 2, the availability is the smallest. This result occurs because the satellite geometry is not good at that point and could not pass the "onboard monitors of GAST D approach".

Simulation results for the approach path simulations

To take into consideration the Hatch filter initialization time of $200 \mathrm{~s}$ for newly rising satellites, a simplified model

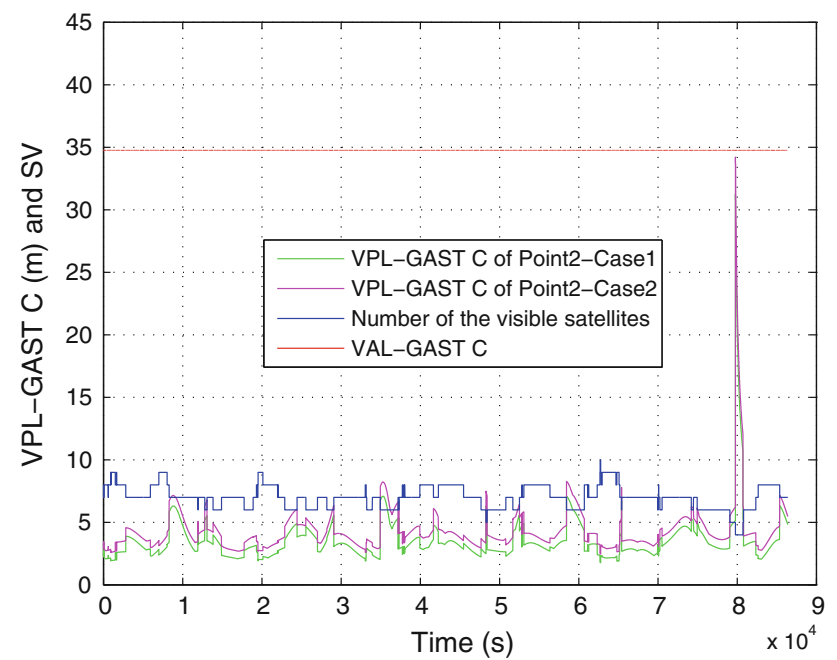

Fig. 6 Simulation results of single point for GAST C (GAST C at Point 2) is used in those simulations. At the beginning of the approach in the model, the user computes for each visible satellite the difference in elevation between the first and second epochs; this is labeled 'diff-elva'. If diff-elva is negative, the satellite is setting; therefore, it is to be kept on. If diff-elva is positive, the satellite is rising; hence, a margin of 200 times the diff-elva will be added to its mask angle. During the approach, once one satellite is lost, it can never be used again even if it may appear again, since the approach duration is often less than $200 \mathrm{~s}$.

The baseline 24-slot constellation is also used. Figure 8 illustrates the result of the single approach path in case of GAST D Case 1, where the approach starts at the epoch zero second. It can be seen that if the filter initialization time of $200 \mathrm{~s}$ for newly rising satellites is not considered, the number of visible satellites will be 7 or 8 , whereas it is always equal to 7 in our simulations. For the multi-

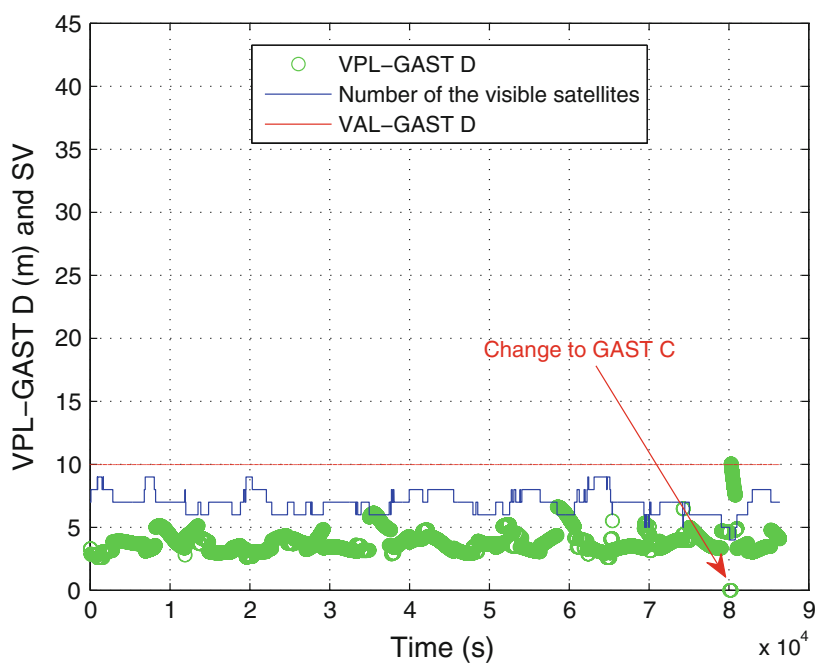

Fig. 7 Simulation results of single point for GAST D (GAST D at Point 3-Case 2)

Table 4 Results of GBAS integrity function availability at each of the 3 single points of LinZhi approach path (SV: number of visible satellites)

\begin{tabular}{|c|c|c|c|c|c|c|c|c|c|c|c|}
\hline \multirow[t]{2}{*}{ Type } & \multirow[t]{2}{*}{ Position H (m) } & \multirow[t]{2}{*}{ Case } & \multicolumn{3}{|c|}{ VPL (m) } & \multicolumn{3}{|l|}{ SV } & \multicolumn{2}{|c|}{ ASTS } & \multirow[t]{2}{*}{ Availability (\%) } \\
\hline & & & Max & Min & Mean & Max & Min & Mean & Num & Percent & \\
\hline \multirow[t]{4}{*}{ GAST C } & Point 1 & Case 1 & 25.78 & 2.10 & 4.65 & 10 & 4 & 6.99 & NA & NA & 99.999 \\
\hline & 500 & Case 2 & 27.76 & 2.74 & 5.39 & & & & & & 99.999 \\
\hline & Point 2 & Case 1 & 31.24 & 1.77 & 3.51 & 10 & 4 & 7.00 & & & 99.999 \\
\hline & 314 & Case 2 & 34.21 & 2.46 & 4.33 & & & & & & 99.999 \\
\hline \multirow[t]{6}{*}{ GAST D } & Point 1 & Case 1 & 24.80 & 3.43 & 6.16 & 10 & 4 & 6.99 & 210 & 0.243 & 99.756 \\
\hline & 500 & Case 2 & 24.80 & 3.43 & 6.16 & & & & 210 & 0.243 & 99.756 \\
\hline & Point 2 & Case 1 & 18.74 & 3.12 & 5.10 & 10 & 4 & 7.00 & 530 & 0.613 & 99.385 \\
\hline & 314 & Case 2 & 18.75 & 3.12 & 5.10 & & & & 530 & 0.613 & 99.385 \\
\hline & Point 3 & Case 1 & 10.05 & 2.59 & 3.82 & 9 & 4 & 6.95 & 211 & 0.244 & 99.747 \\
\hline & 45 & Case 2 & 10.05 & 2.57 & 3.81 & & & & 211 & 0.244 & 99.747 \\
\hline
\end{tabular}


approach simulation, the test duration is $86,400 \mathrm{~s}$ with an interval of $1 \mathrm{~s}$. The 86,400 -second test duration is obtained by concatenating several single approach paths: after a single approach path has been completed, the aircraft is flying the approach path again - that is to say it is going back to the location of Point 1 in Fig. 5, and so on. Figure 9 presents the multi-approach results for both GAST C and GAST D, and Table 5 shows the extracted figures. For GAST C, when the number of visible satellites is 4 , the satellite geometry becomes worse causing the VPL value to increase significantly up to $1,816.6 \mathrm{~m}$. Note that the $y$-scale of Fig. 9 (top) has been limited to $45 \mathrm{~m}$. As in Table 4, it can be noticed in Table 5 that if the filter initialization time of $200 \mathrm{~s}$ for newly rising satellites is not considered, the average number of visible satellites will increase and the VPL will decrease. In that table, a single approach is claimed to be unavailable
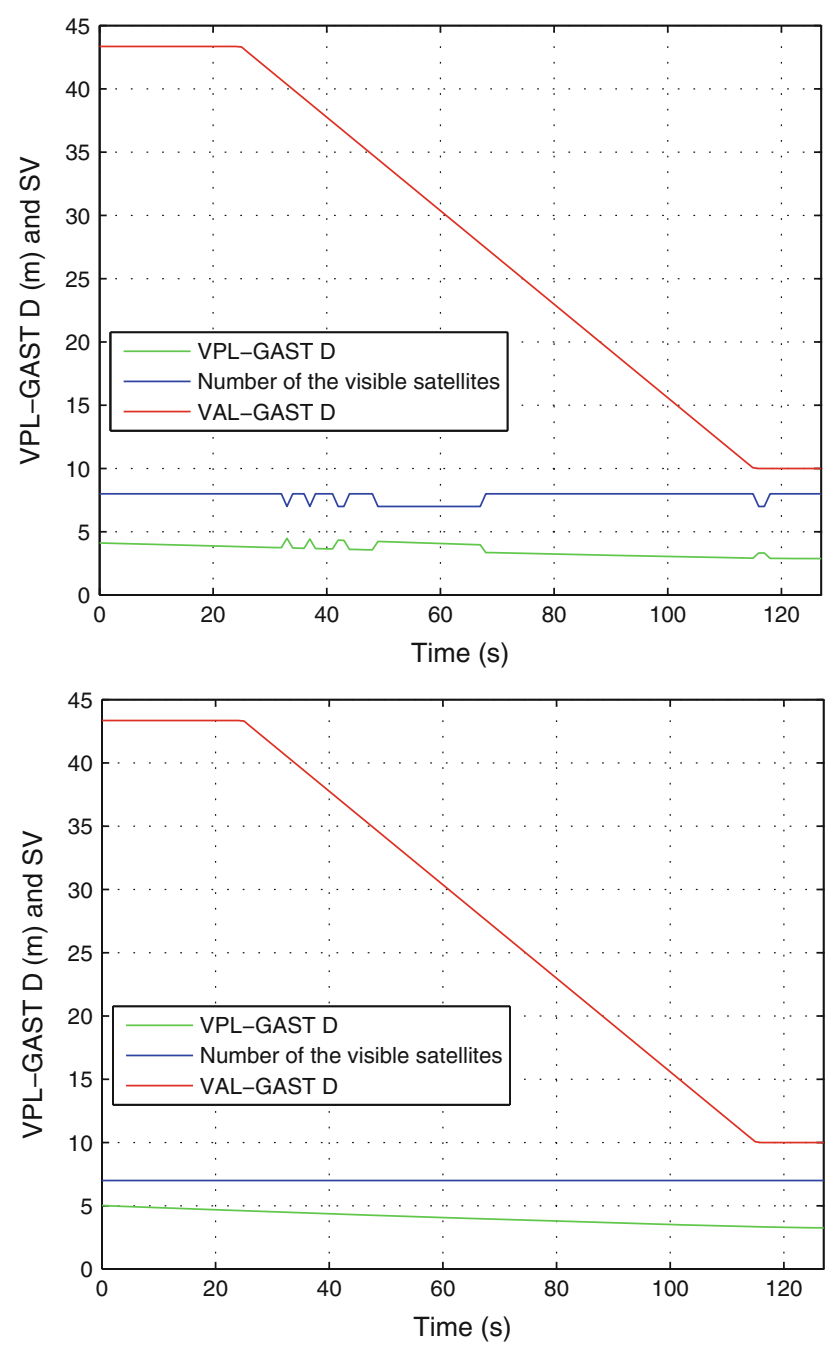

Fig. 8 Impact of the filter initialization time of $200 \mathrm{~s}$ on newly rising satellites. Filter initialization time not considered (top), filter initialization time considered (bottom) whenever there is an epoch in which VPL is bigger than VAL. Thus for Case 1 and Case 2 simulations of GAST $\mathrm{C}$, whether or not the filter initialization time of $200 \mathrm{~s}$ is taken into account, the number of unavailable approaches is 6 , leading to a percentage of unavailable approach over a given day of $0.76 \%$. The same is observed for GAST $\mathrm{D}$, except the unavailable approach percentage is $2.40 \%$ that is to say it is more than three times than that of GAST C.

Impact of mask angle, constellation, and airport latitude on the GBAS Approach Service availability

In this section, we use the software prediction tool to assess the impact of three parameters on the GBAS Approach Service availability. Those parameters are the mask angle, the constellation, and the airport latitude.
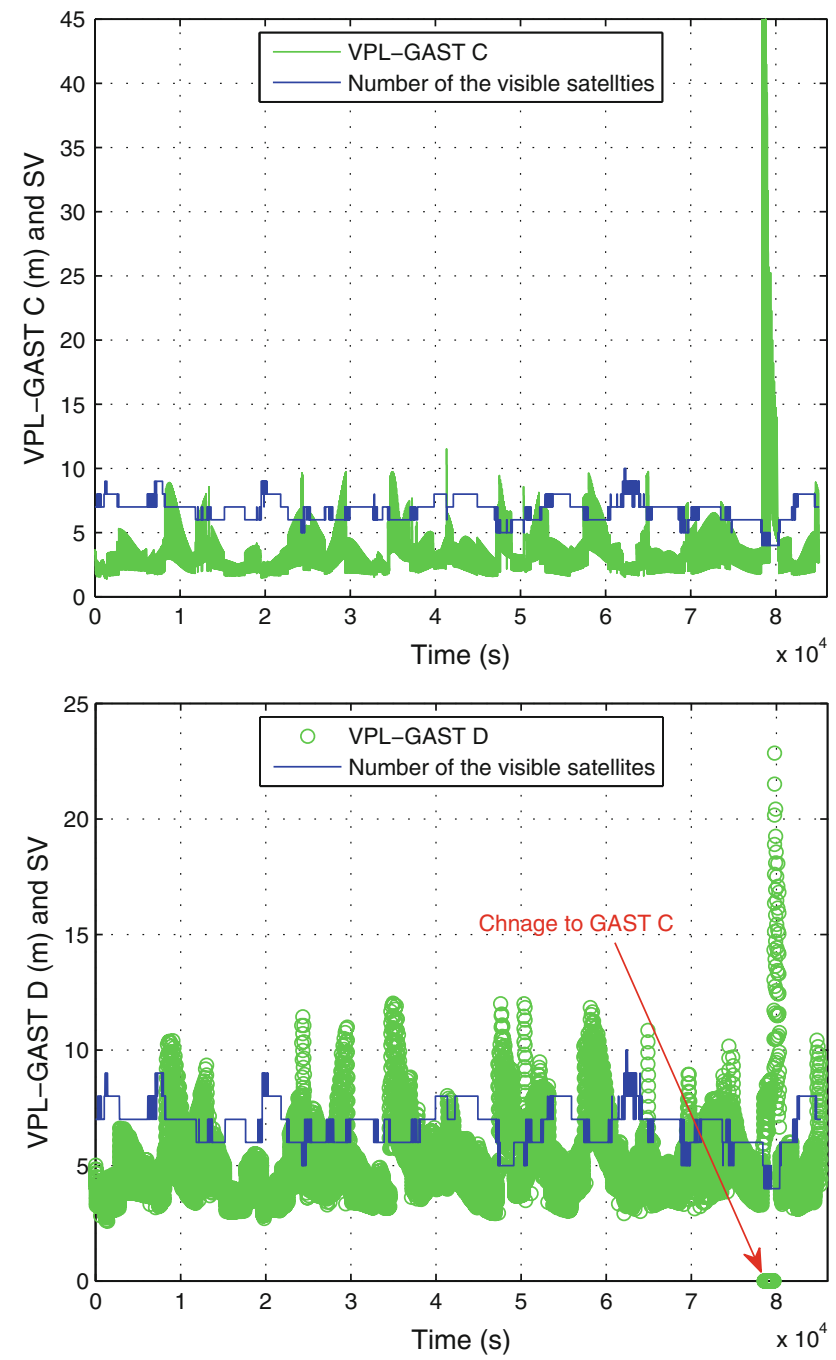

Fig. 9 The VPL and number of the visible satellites (initialization time $200 \mathrm{~s}$ is considered). GAST C Case1 (top), GAST D Case 1 (bottom) 
Table 5 Results of the GBAS approach service availability simulations results at LinZhi airport

\begin{tabular}{|c|c|c|c|c|c|c|c|c|c|c|}
\hline \multirow[t]{2}{*}{ Type } & \multirow[t]{2}{*}{ Case } & \multirow[t]{2}{*}{ Consider $200 \mathrm{~s}$} & \multicolumn{3}{|l|}{ VPL(m) } & \multicolumn{3}{|l|}{ SV } & \multicolumn{2}{|c|}{ Unavailable } \\
\hline & & & Max & Min & Mean & Max & Min & Mean & Number & Percent \\
\hline \multirow[t]{4}{*}{ GAST C } & \multirow[t]{2}{*}{ Case 1} & Yes & $1,781.22$ & 1.36 & 4.01 & 10 & 4 & 6.76 & $6 / 788$ & 0.76 \\
\hline & & No & $1,781.22$ & 1.40 & 3.41 & 10 & 4 & 7.00 & $6 / 788$ & 0.76 \\
\hline & \multirow[t]{2}{*}{ Case 2} & Yes & $1,816.61$ & 2.20 & 4.89 & 10 & 4 & 6.76 & $6 / 788$ & 0.76 \\
\hline & & No & $1,816.61$ & 2.19 & 4.25 & 10 & 4 & 7.00 & $6 / 788$ & 0.76 \\
\hline \multirow[t]{4}{*}{ GAST D } & \multirow[t]{2}{*}{ Case1 } & Yes & 23.53 & 2.58 & 5.14 & 10 & 4 & 6.75 & $16 / 666$ & 2.40 \\
\hline & & No & 23.53 & 2.57 & 4.82 & 10 & 4 & 7.00 & $16 / 666$ & 2.40 \\
\hline & \multirow[t]{2}{*}{ Case 2} & Yes & 23.53 & 2.56 & 5.14 & 10 & 4 & 6.75 & $16 / 666$ & 2.40 \\
\hline & & No & 23.53 & 2.56 & 4.82 & 10 & 4 & 7.00 & $16 / 666$ & 2.40 \\
\hline
\end{tabular}

Based on the above results, we saw for single point simulations the availability of the Approach Service with GAST $\mathrm{C}$ assumptions at each of the three single point in LinZhi airport approach path to be up to $99.999 \%$; the availability with GAST D assumptions is the worst at Point 2 , whereas the availabilities at Point 1 and Point 3 (which is expected to be the worse) are similar. Therefore, the Point 2 and Point 3 locations are chosen to analyze the impact of the former three factors on the availability performance assuming GAST D level service. Furthermore, over a 24-h period, our simulations showed that the number of unavailable approaches in case of Cases 1 and 2 for both GAST C and GAST D is the same. Therefore, the Case 2 is also chosen for both GAST C and GAST D to analyze the impact of mask angle, constellation, and airport latitude parameters on the GBAS Approach Service availability.

Impact of the mask angle

To analyze the impact of the satellites masking angle, the terrain masking is ignored and only the receiver 5-degree mask angle is considered. Figure 10 presents the impact of the mask angle based on single approach path for GAST D in Case 2. In the case where the terrain masking is considered, the Approach Service Type changes from D to C at epoch 32 when the number of visible satellites decreases to 4. In the case where the terrain masking is not considered, the number of visible satellites is always 7 , and a successful GAST D approach may be completed. Table 6 and Table 7 illustrate the figures drawn from the mask angle impact on single point and multi-approach simulations. In these tables, we see that if the terrain masking is not taken into account, the results are better. The signals masking caused by the mountains have a very strong impact on GBAS Approach Service availability at LinZhi airport.

In fact, the case in which the mask angle is chosen as the larger of the terrain mask angle and the receiver 2-degree mask angle (McDonald and Kendrick 2008) has also been simulated. Because there are no error models for a receiver 2-degree mask angle, the parameters for a receiver 5-degree mask angle are used when computing $\sigma_{\text {pr_gnd_x }, i}$. The results are similar to those in Tables 6 and 7 . The
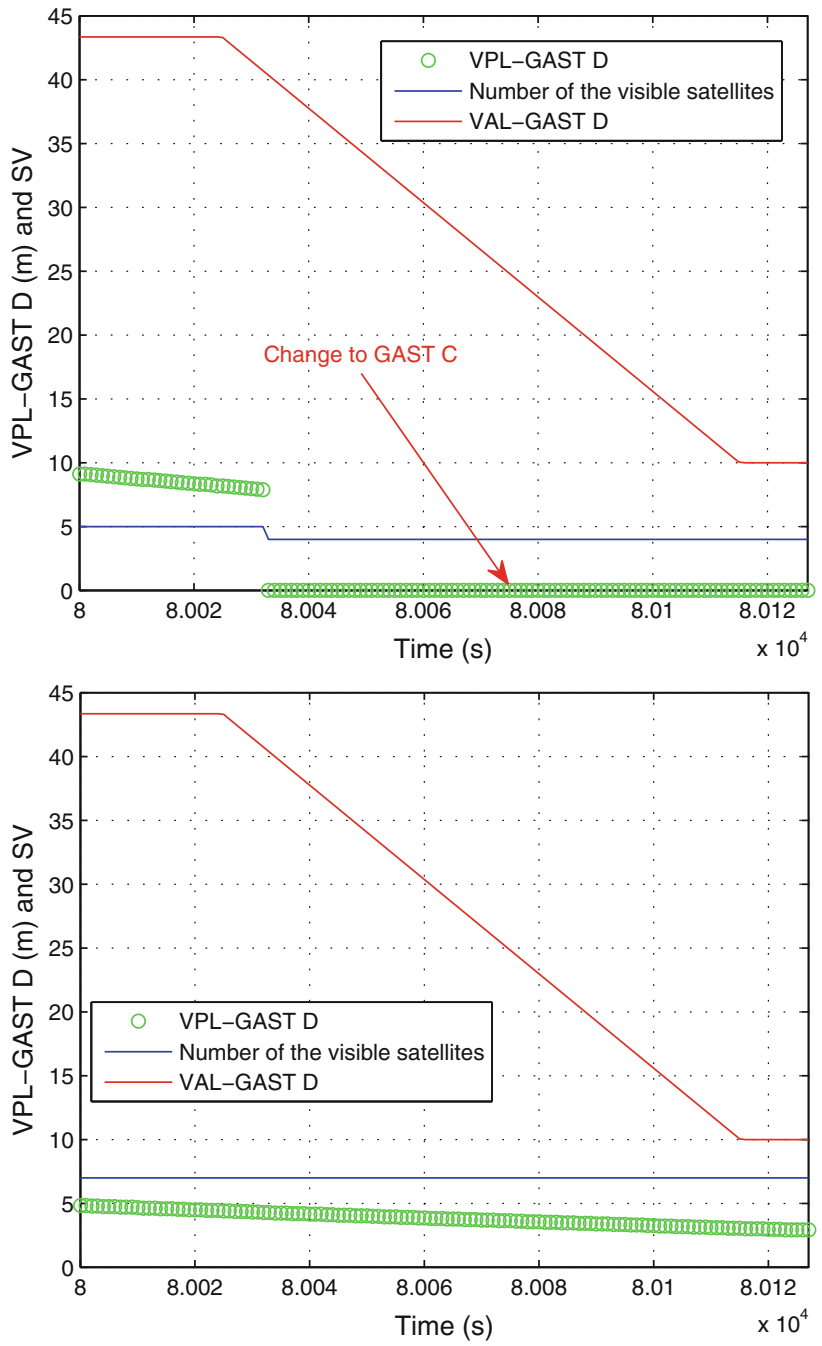

Fig. 10 Impact of the mask angle: terrain masking and receiver 5-degree mask angle (top), receiver 5-degree mask angle, only (bottom) 
number of ASTS, the availability of single point, and the number of unavailable approaches are the same; only the means of VPLs are slightly different.

Impact of the constellation

In the simulations, the GBAS Approach Service availability is computed based on the current constellation almanac provided by the United States Coast Guard. Figure 11 shows the results of a typical example of the constellation impact based on single approach path assuming GAST D service level in Case 2. We see that, using the current constellation, the number of visible satellites is always 8 and the computed VPL values are lower than $4 \mathrm{~m}$. Using the 24-slot baseline constellation, the number of visible satellites is only 4 and the VPL values go from 8 to $22 \mathrm{~m}$. Tables 8 and 9 illustrate the results for constellation impact on single point and multi-approach simulations. It can be seen that for single point, the long-term service availability for GAST C and GAST D is $99.999 \%$; for multi-approach, the unavailable percentage of GAST C and GAST D is 0.38 and $1.95 \%$, respectively.

Impact of the airport latitude

Besides the mask angle and the constellation, the LinZhi airport latitude also has an important impact on the GBAS Approach Service availability. Indeed, for a given longitude, assuming we are in open-sky, if the user moves from zero latitude to latitude $80^{\circ}$, we observe the computed VDOP value to increase and the computed HDOP value to decrease significantly, and the number of visible satellites is bigger at low-latitudes and high-latitudes than as middlelatitudes. Whereas for given latitude, if the user moves in longitude, we observe only a few changes in the number of visible satellites as well as in the HDOP and VDOP computed values.

In the simulations, four typical airports are chosen, including an airport at zero latitude, LinZhi airport (latitude: $29.2955^{\circ}$ ), Chicago airport (latitude: $41.9781^{\circ}$ ), and Anchorage airport (latitude: $64.1744^{\circ}$ ). The same terrain data are used, that is the mountains around LinZhi airport are "moved" to other airports. Tables 10 and 11 illustrate the results of varying the airport latitude on single point
Table 7 Impact of mask angle on GBAS approach services at LinZhi airport (Case 2; duration: 86,400 s; interval: $1 \mathrm{~s}$ )

\begin{tabular}{llllcl}
\hline Type & $\begin{array}{l}\text { Mask } \\
\text { angle }\end{array}$ & $\begin{array}{l}\text { Mean VPL } \\
(\mathrm{m})\end{array}$ & $\begin{array}{l}\text { Mean } \\
\text { SV }\end{array}$ & & \multicolumn{2}{l}{ Unavailable } \\
\cline { 5 - 6 } & & & & Number & Percent \\
\hline GAST C & Terrain $\cap 5$ & 4.89 & 6.76 & $6 / 788$ & 0.76 \\
& 5 & 3.55 & 7.61 & $0 / 788$ & 0.00 \\
GAST D & Terrain $\cap 5$ & 5.14 & 6.75 & $16 / 666$ & 2.40 \\
& 5 & 4.21 & 7.61 & $6 / 666$ & 0.90 \\
\hline
\end{tabular}
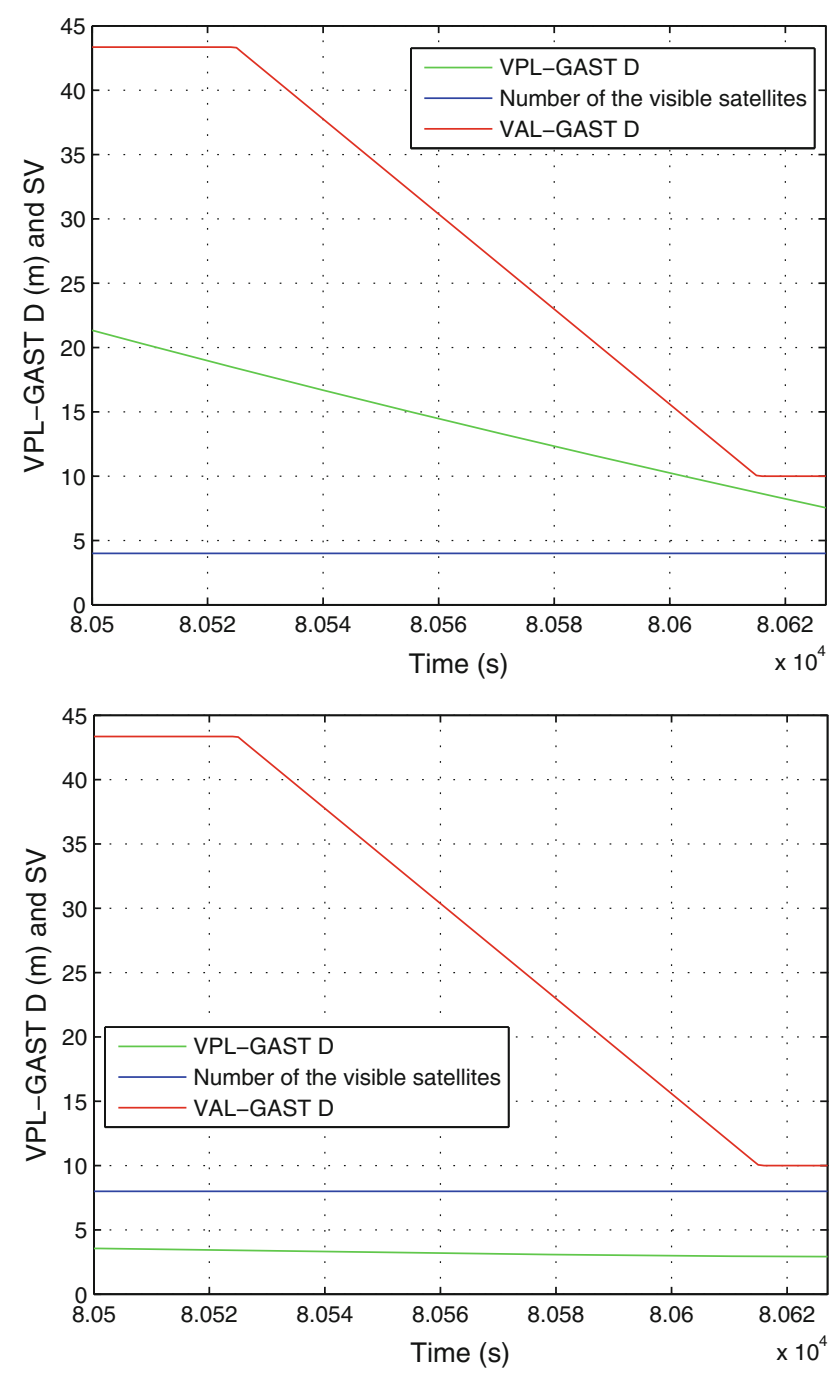

Fig. 11 Impact of the constellation. Baseline 24-slot constellation (top), current constellation (bottom)
Table 6 Results of the impact of mask angle at typical single points of LinZhi approach path (GAST D; Case 2; duration: $86,400 \mathrm{~s}$; interval: $1 \mathrm{~s}$ )

\begin{tabular}{|c|c|c|c|c|c|c|}
\hline \multirow[t]{2}{*}{ Position } & \multirow[t]{2}{*}{ Mask angle } & \multirow[t]{2}{*}{ Mean VPL (m) } & \multirow[t]{2}{*}{ Mean SV } & \multicolumn{2}{|l|}{ ASTS } & \multirow[t]{2}{*}{ Availability (\%) } \\
\hline & & & & Number & Percent & \\
\hline \multirow[t]{2}{*}{ Point 2} & Terrain $\cap 5$ & 5.10 & 7.00 & 530 & 0.613 & 99.385 \\
\hline & 5 & 4.45 & 7.61 & 0 & 0 & 99.999 \\
\hline \multirow[t]{2}{*}{ Point 3} & Terrain $\cap 5$ & 3.81 & 6.95 & 211 & 0.244 & 99.747 \\
\hline & 5 & 3.39 & 7.61 & 0 & 0 & 99.999 \\
\hline
\end{tabular}


and multi-approach simulations. It can be seen that, with the smallest VDOP (because of the smallest latitude) and the most visible satellites, the results for the Lat 0 airport are the best out of the four airports. The results for Chicago airport are similar to those of LinZhi airport, and they are all worse than the results for Lat 0 and Anchorage airports. Although the VDOP of Chicago airport is smaller than that of Anchorage airport, the number of visible satellites of the airport is less than that for Anchorage airport and eventually reduces to 4 , which leads to a bad geometry, similar to the case at LinZhi airport.

\section{Conclusions}

A software tool for GBAS Approach Service availability prediction-based on integrity monitoring function availability assessment-has been implemented. Many simulations have been conducted to evaluate the GBAS Approach Service performance at LinZhi airport, in particular. That airport is located inside the high mountains of Tibet, and these mountains imply the need for precision Approach Service but at the same time may limit GNSS availability. For that purpose, we focused on different flight trajectories: a typical approach flight path and 3 fixed points that are typical points in that path. We assumed several types of airborne and ground sub-systems performances that are characterized either by the AAD, or by the GAD and the number of ground sub-system reference receivers $(M)$. Availability figures are evaluated by varying several other parameters such as latitude or constellation to isolate the specific impact of mountains on that availability performance.

The first set of simulations has been conducted at LinZhi airport with a reduced constellation that is commonly used for performance assessment (baseline 24-slot constellation is used (DoD 2008)). The simulations results show that for GAST D service level, the Approach Service availability with 3 reference receivers $(M=3)$ is the same as with 4 reference receivers. Because of the mountains around the airport, and the reduced number of satellites in the constellation, the number of visible satellites at LinZhi airport may be as low as 4 . The long-term service availability of two typical single points in the approach path has also been
Table 9 Impact of the constellation on GBAS Approach Services at LinZhi airport (Case 2; mask angle: $5^{\circ}$; duration: $86,400 \mathrm{~s}$; Interval: $1 \mathrm{~s})$

\begin{tabular}{clllcl}
\hline Type & Constellation & $\begin{array}{l}\text { Mean VPL } \\
(\mathrm{m})\end{array}$ & $\begin{array}{l}\text { Mean } \\
\text { SV }\end{array}$ & \multicolumn{2}{l}{ Unavailable } \\
\cline { 5 - 6 } & & 4.89 & 6.76 & $6 / 788$ & 0.76 \\
\hline GAST & Bas & 2.87 & 8.70 & $3 / 788$ & 0.38 \\
C & Cur & 5.14 & 6.75 & $16 / 666$ & 2.40 \\
GAST & Bas & 4.25 & 8.68 & $13 / 666$ & 1.95 \\
D & Cur & & & \\
\hline
\end{tabular}

analyzed. For GAST C service level, it is $99.999 \%$, whereas for GAST D service level, it is lower than $99.8 \%$. The percentage of unavailable Approach Services is $0.76 \%$ for GAST C and $2.40 \%$ for GAST D over a $24-\mathrm{h}$ period.

Then, we analyzed the impact of three parametersmask angle, the constellation, and the airport latitude-on the GBAS Approach Service availability.

As to the mask angle, it appears that the terrain masking due to the airport location has a non-negligible impact on the Approach Service availability prediction results. Indeed, if the terrain masking is not taken into account, assuming the receiver mask angle is $5^{\circ}$, the long-term service availability at typical points in the approach path to LinZhi airport will be $99.999 \%$ for GAST D service level; and the percentage of unavailable approaches over $24 \mathrm{~h}$ will be of $0.0 \%$ for GAST C and of $0.9 \%$ for GAST D.

As to the constellation, if the current constellation is used instead of the baseline 24-slot constellation, the longterm service availability at typical points in the approach path to LinZhi airport will be of $99.999 \%$ for GAST D service level; and the percentage of unavailable approaches over a 24-h period will be of $0.38 \%$ for GAST C and of $1.95 \%$ for GAST D. That is to say, the percentage of unavailable approaches over $24 \mathrm{~h}$ without taking into account the terrain masking is $0.38 \%$ for GAST C and $1.05 \%$ for GAST D smaller than those of using the current constellation. Therefore, compared with the mask angle impact, the impact of the constellation on the GBAS Approach Service availability at LinZhi airport is smaller.

As to the latitude, it appears that for airports located near the equator or at $64^{\circ}$ latitude (like Anchorage), but otherwise have the same geographic environment as LinZhi, the
Table 8 Impact of the constellation at typical single points of LinZhi approach path (GAST D; Case 2; mask angle: $5^{\circ}$; duration: $86,400 \mathrm{~s}$; interval: $1 \mathrm{~s}$; bas: baseline 24-slot constellation; cur: current constellation)

\begin{tabular}{lllllll}
\hline Position & Constellation & Mean VPL (m) & Mean SV & \multicolumn{2}{l}{ ASTS } & Availability (\%) \\
\cline { 5 - 6 } & & & & Number & Percent & \\
\hline Point 2 & Bas & 5.10 & 7.00 & 530 & 0.613 & 99.385 \\
& Cur & 4.22 & 9.03 & 0 & 0 & 99.999 \\
Point 3 & Bas & 3.81 & 6.95 & 211 & 0.244 & 99.747 \\
& Cur & 3.24 & 8.98 & 0 & 0 & 99.999 \\
\hline
\end{tabular}


Table 10 Impact of the latitude at typical single points of the approach path for different airport locations (GAST D; case 2; mask angle: $5^{\circ}$; duration: 86,400 s; interval: $1 \mathrm{~s}$; baseline 24-slot constellation)

\begin{tabular}{|c|c|c|c|c|c|c|}
\hline \multirow[t]{2}{*}{ Position } & \multirow[t]{2}{*}{ Airport } & \multirow[t]{2}{*}{ Mean VPL (m) } & \multirow[t]{2}{*}{ Mean SV } & \multicolumn{2}{|l|}{ ASTS } & \multirow[t]{2}{*}{ Availability (\%) } \\
\hline & & & & Number & Percent & \\
\hline \multirow[t]{4}{*}{ Point2 } & Lat 0 & 4.48 & 8.32 & 0 & 0 & 99.999 \\
\hline & LinZhi & 5.10 & 7.00 & 530 & 0.61 & 99.385 \\
\hline & Chicago & 5.12 & 7.10 & 554 & 0.64 & 99.307 \\
\hline & Anchorage & 4.81 & 8.22 & 0 & 0 & 99.999 \\
\hline \multirow[t]{4}{*}{ Point3 } & Lat 0 & 3.60 & 7.93 & 0 & 0 & 99.999 \\
\hline & LinZhi & 3.81 & 6.95 & 211 & 0.244 & 99.747 \\
\hline & Chicago & 3.88 & 6.80 & 198 & 0.229 & 99.612 \\
\hline & Anchorage & 3.63 & 7.72 & 64 & 0.074 & 99.971 \\
\hline
\end{tabular}

Table 11 Impact of the latitude on GBAS approach services (Case 2; mask angle: $5^{\circ}$; duration: $86,400 \mathrm{~s}$; interval: $1 \mathrm{~s}$; baseline 24 -slot constellation)

\begin{tabular}{clllcl}
\hline Type & Airport & $\begin{array}{l}\text { Mean VPL } \\
(\mathrm{m})\end{array}$ & $\begin{array}{l}\text { Mean } \\
\text { SV }\end{array}$ & \multicolumn{2}{c}{ Unavailable } \\
\cline { 5 - 6 } & & & & Number & Percent \\
\hline GAST & Lat 0 & 3.50 & 7.7431 & $0 / 788$ & 0.00 \\
C & LinZhi & 4.89 & 6.7645 & $6 / 788$ & 0.76 \\
& Chicago & 4.79 & 6.6297 & $7 / 788$ & 0.89 \\
& Anchorage & 3.98 & 7.5988 & $2 / 788$ & 0.25 \\
GAST & Lat 0 & 4.49 & 7.7227 & $1 / 666$ & 0.15 \\
D & LinZhi & 5.14 & 6.7461 & $16 / 666$ & 2.40 \\
& Chicago & 5.25 & 6.6124 & $17 / 666$ & 2.55 \\
& Anchorage & 4.59 & 7.5846 & $4 / 666$ & 0.51 \\
\hline
\end{tabular}

long-term service availability at typical points in the approach path will be of $99.999 \%$ for GAST D service level. Over a 24-h period, the Approach Service will always be available for GAST C, and there will be only $0.15 \%$ of unavailable approaches in case of GAST D. This is because the closer the user is to the equator, the smaller the VDOP. In the middle-latitudes (about $25-45^{\circ}$ ), the minimum number of visible satellites might be reduced to 4 in case of a mountainous environment comparable to that of LinZhi, which will result in larger VPL values and could thus reduce the GBAS Approach Service availability.

Thus, it appears from these simulations that the GAST D unavailability of $2.40 \%$ observed with the baseline 24-slot constellation is not only due to the fact that this GAST D approach is implemented in high mountain areas but also because the airport is at mid-latitude.

In this research, the software tool for GBAS Approach Service availability prediction is mainly used to discuss the Approach Service availability at LinZhi airport for GAST $\mathrm{C}$ and GAST D service levels. In fact, the prediction tool could also be expanded to analyze other performances of GBAS, such as Terminal Area Path (TAP) Service and Positioning Service. Furthermore, it could also be used to analyze and optimize the GBAS ground facility location, especially for an airport where the GBAS ground facility is planned to be installed but its position has not yet been chosen, and the geographic environment might impose constraints.

Acknowledgments Funding support from the National Basic Research Program of China (Grant No. 2011CB707004), the National Natural Science Foundation of China (Grant No. 61079016), and the National Key Technologies R\&D Program of China (Grant No. 2011BAH24B02) are appreciated.

\section{References}

Bruckner B, van Graas F, Skidmore T (2011a) Approximations to composite GPS protection levels for aircraft precision approach and landing. GPS Solut 15(4):333-344

Bruckner B, van Graas F, Skidmore T (2011b) Statistical characterization of composite protection levels for GPS. GPS Solut 15(3):263-273

Dautermann T, Felux M, Grosch A (2012) Approach service type D evaluation of the DLR GBAS testbed. GPS Solut 16(3):375-387

DoD (2008) Global positioning system standard positioning service performance standard, US DoD

EUROCAE ED114 (2003) Minimum operational performance specification for global navigation satellite ground based augmentation system ground equipment towards support category I operations. Tech Rep, ED-114, EUROCAE

FAA (2005) Category I local area augmentation system ground facility-NON-FED specification, NON-FED Specification FAA-E-AJW44-2937A, Federal Aviation Administration

Harris M, Murphy T (2007) Geometry screening for GBAS to meet CAT III integrity and continuity requirements. Proc, ION NTM 2007, The Institute of navigation, San Diego, pp 1221-1233

ICAO NSP (2009) GBAS GAST-D (CAT IIIB) Aircraft monitor performance requirements for single reference receiver faults, International Civil Aviation Organization

ICAO NSP (2010a) GBAS CAT II/III development baseline SARPs, International Civil Aviation Organization

ICAO NSP (2010b) Validation of ionospheric anomaly mitigation for GAST D, International Civil Aviation Organization

ICAO Annex 10 (2010) International Standards and recommended practices, Aeronautical Telecommunications-volume I (Radio Navigation Aids), Amendment 85 
McDonald J, Kendrick J (2008) Benefits of Tightly Coupled GPS/IRS for RNP Operations in Terrain Challenged Airports. Proceedings of IEEE/ION PLANS 2008, Monterey, pp 294-303

Neri P, Macabiau C, Azoulai L, Muller J (2010). GBAS NSE model for CAT II/III autoland simulations. Proceedings of IEEE/ION PLANS 2010, Indian Wells, pp 694-707

Pullen S, Lee J, Luo M, Pervan B, Chan F, Gratton L (2001) Ephemeris protection level equations and monitor algorithms for GBAS. Proceedings of ION GPS 2001, The Institute of Navigation, Salt Lake City, pp 1738-1749

RTCA DO245A (2004) Minimum aviation system performance standards for the local area augmentation system (LAAS), Tech Rep, DO245A, RTCA

RTCA DO253C (2008) Minimum operational performance standards for GPS local area augmentation system airborne equipment, Tech Rep DO253C, RTCA

RTCA DO246D (2009) GNSS based precision approach local area augmentation system (LAAS) signal-in-space interface control document (ICD), Tech Rep DO246D, RTCA

Shively CA (1993) Satellite criticality concepts for unavailability and unreliability of GNSS satellite navigation. J Inst Navig 40(4):429-450

Shively CA (2004) Availability enhancements for CAT IIIB LAAS. J Inst Navig 51(1):45-58

Shively CA, Hsiao TT (2010) Availability of GAST D GBAS considering continuity of airborne monitors. Proceedings of ION ITM 2010, San Diego, pp 365-375

Xie G, Pullen S, Luo M, Normark P et al (2001) Integrity design and updated test results for the Stanford LAAS integrity monitor testbed. In: Proceedings of the ION 57th annual meeting and the CIGTF 20th biennial guidance test symposium, Albuquerque, pp 681-693

\section{Author Biographies}

Zhipeng Wang is a Ph.D. candidate in the National Key Laboratory of CNS/ATM (Communication, Navigation, surveillance/Air Traffic Management) in the School of Electronic Information and Engineering, Beihang University. He received a B.S. degree from the School of Electronic Information and Engineering, Northwestern Polytechnical University (NWPU). His research focuses on the algorithms design of ground-based augmentation system (GBAS) and satellitebased augmentation system (SBAS).

Christophe Macabiau graduated as an electronics engineer in 1992 from the ENAC in Toulouse, France. Since 1994, he has been working on the application of satellite navigation techniques to civil aviation. He received his Ph.D in 1997 and has been in charge of the signal processing laboratory of ENAC since 2000. He is now the head of the Telecom Lab at ENAC.

Jun Zhang received B.S., M.S. and Ph.D. degrees from the School of Electronic Information Engineering, Beihang University in 1987, 1990, and 2001 respectively. He is currently a professor at Beihang University and Director of CNS/ATM labs, CAAC. His major research interests are air traffic management, aeronautical telecommunication network, and satellite navigation.

Anne-Christine Escher graduated as an electronics engineer in 1999 from the ENAC in Toulouse, France. Since 2002, she has been working as a teacher and researcher in the signal processing and navigation research group at the TELECOM Lab. of ENAC. She received her Ph.D. in 2003. 